\title{
Study of autoantibodies in patients with keratoconjunctivitis sicca infected by the human $T$ cell lymphotropic virus type 1
}

\author{
Ana Karina Ferraz-Chaoui $\cdot$ Ajax Mercês Atta $\cdot$ \\ Maria Luiza Sousa Atta $\cdot$ Bernardo Galvão-Castro • \\ Mittermayer B. Santiago
}

Received: 5 January 2009 / Accepted: 12 July 2009 / Published online: 29 July 2009

(C) Springer-Verlag 2009

\begin{abstract}
Human $\mathrm{T}$ cell lymphotropic virus type 1 (HTLV-1) is endemic in many regions of the world, including Brazil, and has been associated to several immunological manifestations such as arthritis, uveitis, dermatitis and Sjögren's syndrome. This study was intended to evaluate the frequency of autoantibodies in patients infected with HTLV-1 and manifesting keratoconjunctivitis sicca (KCS). HTLV-1 patients with KCS, enrolled in a reference ambulatory of the city of Salvador, were tested for autoantibodies such as antinuclear antibodies, rheumatoid factor, antiSSA/Ro and anti-SSB/La. Two comparison groups were also included: (a) HTLV-1 patients without KCS and (b) seronegative patients with KCS. Correlation of proviral load (PVL) in HTLV-1 patients with presence or absence of KCS was also assessed. No autoantibodies were detected in HTLV-1 patients with KCS. The PVL of HTLV-1 patients
\end{abstract}

\footnotetext{
A. K. Ferraz-Chaoui

Instituto Brasileiro de Oftalmologia e Prevenção à Cegueira

[Brazilian Institute for Ophthalmology and Prevention of Blindness], Escola Bahiana de Medicina e Saúde Pública (EBMSP), Salvador, Brazil
}

\author{
A. M. Atta - M. L. S. Atta \\ Immunology Research Laboratory, Department of the UFBA, \\ Clinical and Toxicological Analysis, Faculty of Pharmacy, \\ UFBA, Salvador, Brazil \\ B. Galvão-Castro \\ HTLV/Viral Hepatitis Integrative Center \\ of EBMSP/FBDC/FIOCRUZ, EBMSP, Salvador, Brazil
}

M. B. Santiago ( $\square)$

Serviço de Reumatologia do HSI, EBMSP,

Praça Conselheiro Almeida Couto, 500, Nazaré,

CEP 40000-000 Salvador, Bahia, Brazil

e-mail: mitter@svn.com.br was higher in patients with KCS without other clinical manifestations customarily associated to HTLV-1. In conclusion, in this study, no changes were observed in humoral immunity concerning production of certain autoantibodies in HTLV-1-infected patients with KCS, which suggests that other mechanisms may be involved in the pathogenesis of this manifestation. Additionally, PVL may be a marker of KCS development in these patients.

Keywords HTLV-1 - Autoantibodies . Keratoconjunctivitis sicca $\cdot$ Proviral load

\section{Introduction}

Retroviruses were first described in the beginning of the last century, but the causal relationship with human diseases was only established in the early 1980s when human $\mathrm{T}$ cell lymphotropic virus type 1 (HTLV-1) was identified as an etiologic agent of leukemias and lymphomas [1].

This virus has shown high levels of endemicity in some regions of the globe, such as southwest Japan, the Caribbean, Central and South America, Melanesia and Africa [2]. In Brazil, it is estimated that 750,000 subjects are infected [3] and in the city of Salvador, a recent seroprevalence study has shown that $1.7 \%$ of the population is infected [4], the highest seroprevalence found in the country.

Two clinical conditions were initially associated to infection by HTLV-1-adult T cell leukemia-lymphoma [5] and HTLV-1-associated myelopathy/tropical spastic paraparesis (HAM/TSP) [6]. Additionally, many authors have demonstrated a possible causal relationship between cases of arthritis [7, 8], polymyositis [9] and Sjögren's syndrome (SS) $[10,11]$ and infection by this virus, which 
suggests direct action of this agent on auto-immunity. Ophthalmological manifestations such as uveitis [12], corneal changes $[13,14]$ and keratoconjunctivitis sicca (KCS) $[15,16][17]$ may also occur:

This study was intended to evaluate the presence of certain autoantibodies in patients with HTLV-1 infection complicated by KCS, and to investigate association between the proviral load (PVL) and this complication.

\section{Materials and methods}

\section{Subjects}

Three subject cohorts were investigated. (a) Cohort I: 15 patients with serum diagnosis of HTLV-1 infection (ELISA and Western blot) followed up in the outpatient clinic of HTLV/Viral Hepatitis Integrative Center of EBMSP/FIOCRUZ, and diagnosis of KCS based on the European Community Criteria for SS [18]. (b) Cohort II: 15 patients with HTLV-1 without KCS paired by sex and age with the previous group and proceeding from the same outpatient clinic. (c) Cohort III: $14 \mathrm{KCS}$ patients with negative serology for HTLV-1 (ELISA), selected from the outpatient clinic of the Brazilian Institute for Ophthalmology and Prevention of Blindness (IBOPC).

Patients who refused to participate in the project were excluded from the study, as well as patients with KCS secondary to other previously diagnosed diseases, such as Steven-Johnson syndrome, ocular burns, eyelid occlusion deficit, collagen vascular diseases, previous herpes virus infection and refractive surgeries.

In addition to the complete ophthalmological examination and the lacrimal function tests, all patients underwent serum tests for autoantibodies: antinuclear antibodies (ANA) by indirect immunofluorescence on HEp-2 cells, rheumatoid factor (RF) by nephelometry and anti-SSA/Ro and anti-SSB/La tested by ELISA. Additionally, PVL was quantified in subjects of cohorts I and II (HTLV-1-infected) using the "TaqMan real-time PCR assay" [19].

Statistical analysis was conducted using the software Statistical Package for the Social Sciences (SPSS Chicago, IL, version 13). Some results were expresses as a mean \pm standard deviation. The Mann-Whitney test was used for median comparison, after testing the normality of quantitative variables. The normality was tested using the D'Agostino Pearson method. For all statistical tests, a $P$ value $<0.05$ was considered. The study was approved by the Ethics Committee of Hospital Santa Izabel and all patients signed an informed consent form before entering the study.
Table 1 Clinical conditions associated to infection by HTLV-1 in cohorts I (HTLV-1-infected with KCS) and II (HTLV-1-infected without KCS)

\begin{tabular}{lcc}
\hline Clinical picture & $\begin{array}{l}\text { Cohort I } \\
N(\%)\end{array}$ & $\begin{array}{l}\text { Cohort II } \\
N(\%)\end{array}$ \\
\hline HAM/TSP & $6(40)$ & $3(20)$ \\
Suspected HAM/TSP & $1(6.6)$ & $3(20)$ \\
Other manifestations of HTLV-1 & $1(6.6)$ & 0 \\
No other clinical manifestations & $7(46.6)$ & $6(60)$ \\
Total & $15(100)$ & $15(100)$ \\
\hline
\end{tabular}

KCS keratoconjunctivitis sicca, HAM/TSP, HTLV-1-associated myelopathy/tropical spastic paraparesis

\section{Results}

Cohorts I and II had 15 patients each, of which six were males $(40.0 \%)$ and nine females $(60.0 \%)$, with mean age of $53.1 \pm 14.2$ years in the first cohort and $50 \pm 13.1$ years in the second. Cohort III was composed of 14 patients, of which two were males (14.3\%) and 12 females (85.7\%), with mean age of $61.21 \pm 12.3$ years. Nine patients in group I and six patients in group III also had xerostomia as defined by European Community Criteria for SS. Regarding the severity of KCS, all patients in group I were graded as stage 1 whereas in group III, nine were in stage 1 and five in stage 2.

Of the HTLV-1-positive patients with KCS (cohort I), seven were asymptomatic carriers (46.6\%) and eight $(53.3 \%)$ has virus-related diseases; HAM/TSP was confirmed in six patients (40.0\%). Among the HTLV-1positive patients without KCS diagnosis (cohort II), nine (60\%) were asymptomatic. Six $(40.0 \%)$ presented with HTLV-1-related clinical changes, and HAM/TSP was confirmed in three patients (20\%) (Table 1$)$.

In cohorts I and III, no patients was positive for ANA, anti-SSA/Ro, anti-SSB/La or RF, while three of the 15 patients of cohort II (20\%) were positive for RF and negative for other autoantibodies.

When evaluating all HTLV-1 carrier patients (with or without KCS), it was observed that the mean PVL was higher in patients with KCS (125,891 copies) than in patients with preserved lacrimal function (57,555 copies); however, no statistical significance was achieved $(P=0.06)$. Mean PVL was also higher in HAM/TSP carriers $(195,394.8$ copies) than in asymptomatic patients (46,131.81 copies) $(P=0.01)$.

There was no statistically significant difference in the mean PVL among HAM/TSP carrier patients with KCS $(191,545.50)$ and without KCS $(203,093.30)(P=0.9)$. 
However, in non-HAM/TSP patients the presence of KCS was associated to a higher mean PVL $(85,058.63$ copies in KCS patients and 11,481.56 in non-KCS patients), $P=0.01$.

\section{Discussion}

HTLV-1-associated tear film changes were initially noted by Green et al. [20], when studying mice bearing the Tax gene and developing a SS-like clinical picture [20]. The association between SS and HTLV-1 in humans is dated 1992, when Eguchi et al. [10] found in an endemic zone higher prevalence of this virus among the carriers of the syndrome than in the seronegative control group. Curiously, clinical, laboratorial and histopathological similarities have been observed by many authors when comparing patients with SS who show positive or negative serology for HTVL-1. Thus, Hida et al. [21] compared the prevalence of autoantibodies in HTLV-1 positive and negative patients with SS, and did not find any statistically significant differences between the frequency of antibodies antiSSA/Ro, anti-SSB/La, ANA and RF among the two groups investigated. Likewise, Nakamura et al. [22] observed that $65 \%$ of HAM/TSP patients had SS and, among these patients, $61 \%$ were positive for ANA and $38 \%$ had antiSSA/Ro e anti-SSB/La antibodies.

On the other hand, studies conducted in Martinica showed that in HTLV-I patients with KCS associated to infiltration of salivary glands confirmed by biopsy graded according to the Chisholm scale [23], the autoantibodies screening was negative for all patients investigated $[16,24]$. The findings of the present study are similar to those results since SS-marker antibodies such as anti-SSA/Ro and anti$\mathrm{SSB} / \mathrm{La}$ were not found in the population of $30 \mathrm{HTLV}-1$ infected patients, regardless of the presence of KCS.

One limitation of this study is that other manifestations of SS, i.e., the presence of xerostomy and lip biopsy showing lymphocytic infiltrate were not explored and therefore the possibility of the absence of these antibodies being due to selection of cases without complete SS may not be excluded. Another theory is that the HTLV-1 strand existing in Brazil and Martinica might be different from that existing in Japan, which allows infiltration of salivary and lacrimal glands by lymphocyte populations with different capacities to produce autoantibodies. Anyhow, a conclusion can already be drawn from the findings of the present study: the presence of KCS in HTLV-1 patients does not seem to depend on the production of the antibodies as it occurs in most cases of "primary" SS.

Brazil is an endemic zone for HTLV-1 and some studies have confirmed the ocular involvement associated to HTLV-1 [25-27]; however, little has been investigated about the presence of autoantibodies in patients with manifestations of SS. An exception would be the study recently developed at another research site in the same city (Salvador), in which the authors also did not find any anti-SSA/ Ro anti-SSB/La antibodies in HTLV-1-infected patients, even in those with clinical manifestations of SS [28], which reinforces what has been commented before.

Some mechanisms have been proposed for the development of clinical SS manifestations in HTLV-1 carriers, such as: the virus might infect and activate anergic autoreactive $\mathrm{T}$ cells, breaking immunological tolerance; or cellular products bearing the HTLV-1 Tax gene might be candidate autoantigens or might lead to the activation of autoreactive T cells, thus resulting in SS [29].

Despite the small number of subjects enrolled, which requires careful interpretation of statistical findings, another relevant finding of this study was the observation that patients with HTLV-1 and KCS free of any other clinical manifestation customarily associated to this infection showed a higher PVL than those without KCS. These data may suggest that PVL determination could be a marker of KCS development, similarly to what has been seen in patients with uveitis [30]. There is no information on whether this higher viral activity could also lead to inhibition of the production of autoantibodies, which could justify the negative serologic findings of our study. Association between KCS and the presence of HAM/TSP was also observed in our study and is corroborated by previous studies $[31,32]$.

Acknowledgments The authors thank Professor Fernanda Grassi for the excellent suggestions provided during the manuscript preparation. MS received a scholarship from CNPq.

\section{References}

1. Poiesz BJ, Ruscetti FW, Gazdar AF, Bunn PA, Minna JD, Gallo RC (1980) Detection and isolation of type $C$ retrovirus particles from fresh and cultured lymphocytes of a patient with cutaneous T-cell lymphoma. Proc Natl Acad Sci USA 77(12):7415-7419

2. Proietti FA, Carneiro-Proietti AB, Catalan-Soares BC, Murphy EL (2005) Global epidemiology of HTLV-I infection and associated diseases. Oncogene 24(39):6058-6068

3. Galvao-Castro B, Loures L, Rodriques LG et al (1997) Distribution of human T-lymphotropic virus type I among blood donors: a nationwide Brazilian study. Transfusion 37(2):242-243

4. Dourado I, Alcantara LC, Barreto ML, da Gloria Teixeira M, Galvao-Castro B (2003) HTLV-I in the general population of Salvador, Brazil: a city with African ethnic and sociodemographic characteristics. J Acquir Immune Defic Syndr 34(5):527-531

5. Yoshida M, Miyoshi I, Hinuma Y (1982) Isolation and characterization of retrovirus from cell lines of human adult T-cell leukemia and its implication in the disease. Proc Natl Acad Sci USA 79(6):2031-2035

6. Gessain A, Barin F, Vernant JC et al (1985) Antibodies to human T-lymphotropic virus type-I in patients with tropical spastic paraparesis. Lancet 2(8452):407-410 
7. Nishioka K, Maruyama I, Sato K, Kitajima I, Nakajima Y, Osame M (1989) Chronic inflammatory arthropathy associated with HTLV-I. Lancet 1(8635):441

8. Ijichi S, Matsuda T, Maruyama I, Ijichi S et al (1990) Arthritis in a human T lymphotropic virus type I (HTLV-I) carrier. Ann Rheum Dis 49(9):718-721

9. Morgan OS, Rodgers-Johnson P, Mora C, Char G (1989) HTLV-1 and polymyositis in Jamaica. Lancet 2(8673):1184-1187

10. Eguchi K, Matsuoka N, Ida H et al (1992) Primary Sjogren's syndrome with antibodies to HTLV-I: clinical and laboratory features. Ann Rheum Dis 51(6):769-776

11. Terada K, Katamine S, Eguchi K et al (1994) Prevalence of serum and salivary antibodies to HTLV-1 in Sjogren's syndrome. Lancet 344(8930):1116-1119

12. Mochizuki M, Watanabe T, Yamaguchi K et al (1992) HTLV-I uveitis: a distinct clinical entity caused by HTLV-I. Jpn J Cancer Res 83(3):236-239

13. Merle H, Cabre P, Merle S, Gerard M, Smadja D (2001) A description of human T-lymphotropic virus type I-related chronic interstitial keratitis in 20 patients. Am J Ophthalmol 131(3):305-308

14. Buggage RR, Levy-Clarke GA, Smith JA (2001) New corneal findings in human T-cell lymphotrophic virus type 1 infection. Am J Ophthalmol 131(3):309-313

15. Merle H, Smadja D, Le Hoang P, Merle H, Smadja D, Le Hoang P et al (1996) Ocular manifestations in patients with HTLV-I associated infection-a clinical study of 93 cases. Jpn J Ophthalmol 40(2):260-270

16. Merle H, Cabre P, Olindo S, Merle S, Smadja D (2002) Ocular lesions in 200 patients infected by the human T-cell lymphotropic virus type 1 in martinique (French West Indies). Am J Ophthalmol 134(2):190-195

17. Nakamura H, Eguchi K, Nakamura T et al (1997) High prevalence of Sjogren's syndrome in patients with HTLV-I associated myelopathy. Ann Rheum Dis 56(3):167-172

18. Vitali C, Bombardieri S, Moutsopoulos HM et al (1996) Assessment of the European classification criteria for Sjogren's syndrome in a series of clinically defined cases: results of a prospective multicentre study. The European Study Group on Diagnostic Criteria for Sjogren's syndrome. Ann Rheum Dis 55(2):116-121

19. Dehee A, Cesaire R, Desire N et al (2002) Quantitation of HTLVI proviral load by a TaqMan real-time PCR assay. J Virol Methods 102(1-2):37-51

20. Green JE, Hinrichs SH, Vogel J, Jay G (1989) Exocrinopathy resembling Sjogren's syndrome in HTLV-1 tax transgenic mice. Nature 341(6237):72-74
21. Hida A, Kawabe Y, Kawakami A et al (1999) HTLV-I associated Sjogren's syndrome is aetiologically distinct from anti-centromere antibodies positive Sjogren's syndrome. Ann Rheum Dis 58(5):320-322

22. Nakamura H, Kawakami A, Tominaga M et al (2000) Relationship between Sjogren's syndrome and human T-lymphotropic virus type I infection: follow-up study of 83 patients. J Lab Clin Med 135(2):139-144

23. Chisholm DM, Mason DK (1968) Labial salivary gland biopsy in Sjogren's disease. J Clin Pathol 21(5):656-660

24. Merle H, Cabre P, Smadja D, Josset P, Landau M, Vernant JC (1999) Sicca syndrome and HTLV-I-associated myelopathy/tropical spastic paraparesis. Jpn J Ophthalmol 43(6):509-512

25. Pinheiro SR, Lana-Peixoto MA, Proietti AB et al (1995) HTLV-I associated uveitis, myelopathy, rheumatoid arthritis and Sjogren's syndrome. Arq Neuropsiquiatr 53(4):777-781

26. Moraes HV Jr, Branco RL, Pinto CMS, Dantas MM, Fiszman R (1995) HTLV-I e Uveíte. Revista Brasileira de Oftalmologia 54(12):39-42

27. Pinheiro SR, Martins-Filho AO, Ribas JG et al (2006) Immunologic markers, uveitis, and keratoconjunctivitis sicca associated with human T-cell lymphotropic virus type 1 . Am J Ophthalmol 142(5):811-815

28. Giozza SP, Santos SB, Martinelli M, Porto MA, Muniz AL, Carvalho EM (2008) Salivary and lacrymal gland disorders and HTLV-1 infection. Rev Stomatol Chir Maxillofac 109(3):153-157

29. Santiago M, Crusoé EQ, Matos AV (2002) Manifestações reumatológicas associadas à infecção pelo HTLV-I. Rev Bras Reumatol 42(5):306-310

30. Ono A, Mochizuki M, Yamaguchi K, Miyata N, Watanabe T (1995) Increased number of circulating HTLV-1 infected cells in peripheral blood mononuclear cells of HTLV-1 uveitis patients: a quantitative polymerase chain reaction study. Br J Ophthalmol 79(3):270-276

31. Best I, Adaui V, Verdonck K et al (2006) Proviral load and immune markers associated with human T-lymphotropic virus type 1 (HTLV-1)-associated myelopathy/tropical spastic paraparesis (HAM/TSP) in Peru. Clin Exp Immunol 146(2):226-233

32. Montanheiro PA, Oliveira AC, Posada-Vergara MP et al (2005) Human T-cell lymphotropic virus type I (HTLV-I) proviral DNA viral load among asymptomatic patients and patients with HTLVI-associated myelopathy/tropical spastic paraparesis. Braz J Med Biol Res 38(11):1643-1647 